\title{
Remodeling and Reflection of Historic District - Taking Qianmen Street as an example
}

\author{
WANG ZHI ${ }^{1, a}$, \\ ${ }^{1}$ Institution of Agricultural Scientech Information, Beijing Academy of Agriculture and Forestry \\ Sciences, Beijing, 100097 \\ aemail: angelwang1009@163.com
}

Keywords: Historic District, Qianmen Street, Business evolution, Remodeling.

Abstract. Qianmen area is no longer in those years of prosperity spectacular, there is a historical reason, a more important reason is its commercial positioning fuzzy, overall positioning error caused. This paper studies the Qianmen Street commercial development context, to extract the elements of Qianmen Street economy and cultural prosperity. We would like to see through the nature of the phenomenon and find Qianmen Street "soul", which stimulate the revival of the potential for the revival of the historic district of cultural, economic revival and morphological remodeling, providing development ideas and implementation strategies.

\section{Introduction}

Qianmen Street was founded 570 years ago, it is the only way forroyal ritual, hunting, patrol at Ming and Qing Dynasties, known as "Heaven Street". Sedimentary nearly 600 years, making Beijing Qianmen Street became the architectural culture, business culture, cultural hall, opera culture, folk culture precipitate profound characteristic historic district, is one of Beijing landmark. Today, however, Qianmen Street no longer have the same spectacular, so many people confused by its development. History Commercial Streets become ordinary street shops, tasteless attractions. By combing historical context of Qianmen Street, the author were compared for business forms and characteristics in different periods, to extract the Qianmen Street's economic and cultural boom operating mode. We would like to see through the appearance essence, Claim this lost Qianmen Street "soul" unleash the potential of Qianmen Street revival, provide ideas and implementation strategies for the development of the historic district of remodeling.

\section{Overview of Qianmen Street}

Qianmen Street is the most famous commercial street in Qianmen area. It is a traditional Beijing Commercial Street. Located in Beijing's central axis, starts at the northern end of Qianmen Door, reach the southern end of the bridge crossing. Jiajing twenty-nine years (1550), before establishing outside the city, this street was the Royal Road which Ming Royal to the Temple of Heaven, after outside the city was established the street was the main north-south street. It was called as Zhengyang Street by the republic at the Ming and Qing Dynasty, commonly known as Qianmen Street. Since the Republic of China after the liberation, Beijing Qianmen Street has been one of the three most important commercial Old Town streets. It's officially named Qianmen Street in 1965.

Qianmen area is a commercial circle that the center is Qianmen Street, which includes both sides of the fish mouth, Dashanlan Street, Jewelry Street and other traditional city street bazaar. Many old and famous brands located here, it's one of the urban areas of Beijing's most historical and cultural charm.Literature References 


\section{Causes of Qianmen Street boom}

Qianmen Street in history to be Beijing's most bustling commercial street, the reasons are mainly following:

\section{(1) Special location}

It was the only way for royal ritual, hunting, patrol at Ming and Qing Dynasties, known as "Heaven Street". Qianmen Street was also the only way for Beijing businessman. After the Ming Dynasty moved the capital to Beijing, Beijing's commercial center has moved to Qianmen Street. In addition, the expansion outside the city after the Ming Dynasty, the government building houses to attract resident stay in here, and also to attract businessmen operating. Wealthy businessmen in Zhejiang, Suzhou province and other places moved to here, brought prosperity to the region many passengers and goods, and promote the rapid development of all aspects of the Qianmen Area.

(2) Old and famous shop or time-honored brand gathered

Historically, Qianmen Street is a gathering place of time-honored brands, these Old and famous are: Founded in the Qing Tongzhi-three years, as the first Chinese eat named "Quanjude"; founded in Kangxi Dynasty eight years, the country's most famous traditional Chinese medicine hall called "Tong ren-tang Pharmacy"; one of Beijing's oldest opera house, built in 1796, "Guangde Opera House Park," and so on, over twenty Old and famous shops, including the food, clothing, and other life forms.

\section{The outstanding problems facing the Qianmen Street}

2008 years ago, the street door reopened. Now, years later, it has experienced a brilliant century, but was decline of Qianmen Street, still did not revive the glory. Its ability to achieve revival, still faces the following outstanding issues:

\section{(1) Lack of cultural accumulation neither fish nor fowl.}

Qianmen Street attractive is that the old Beijing's history and cultural accumulation however, reopened Qianmen Street, there are many international brands have entered the marketplace Qianmen Street's inherent cultural and historical accumulation has been greatly hurt. And also, the local business climate has been heavy damaged to. There are all kinds of incompatible and inconsistent between Qianmen Street and international brands. The original consumer groups are rapidly lost.

(2) Loss of cultural traditions, a vague position.

Many folklorists believe that the transformation of Qianmen Street is demolished and sacrifice of alleys as the price, lost their original culture label. As the positioning fuzzy, poor management, this ancient street has been reduced to a "dull" attraction.

\section{Ideas and suggestions for Qianmen Street revival and remodeling development}

(1) The Collating of Qianmen Street's value, reasonable positioning its remodeling function.

Business location is a critical decision-making, this is about the historic district remodeling and development success. Qianmen area as commercial district has a rich tradition of historical value, cultural value, artistic value and commercial value, resource value and social value. Must fully understand the basis of these values, in order to objectively and reasonably given the overall positioning of the front door area. 
I believe that the Qianmen Street's revival and remodeling can be positioned as follows: to protect and display the "Civil Culture" as the core, focused on "Beijing old" culture. traditional old, characteristic industry, folk customs as such Qianmen Street both pay their last respects, tourism, recreation, education, dining, shopping and other functions, and ultimately become a commercial, leisure, entertainment, experience is a comprehensive history of one of the commercial cultural areas.

(2) Enhance the cultural connotation of Qianmen Street, making it a tourist destination for the through connection with "Forbidden City, Tiananmen Square and the front door."

Qianmen Street retains the full traditional pattern of streets, many streets, alleys still follow the traditional name of the Ming and Qing Dynasties, become a traditional memory of the city. Courtyards there are an unique urban fabric of traditional Beijing city, are very rich in geographical characteristics.

Qianmen Street as the geographic coordinates of the capital, occupys an excellent central location. Its wide streets scale reinforces the axis of the charm of the ancient city.

Focus on refining the cultural connotation Qianmen Street, depth excavation its special historical position, take advantage of its rich cultural heritage and other physical resources, and actively guide, training people's attention on Beijing folk customs and traditional style. Thereby forming a travel chain throughout "Forbidden City, Tiananmen Square and Qianmen Street", reproduce the old spectacular and reputation of Qianmen Street.

(3) Based on tradition, reasonably and effectively development of Qianmen Street intangible cultural heritage.

Qianmen Street once the "Civil Culture" and "marketplace atmosphere", with rich human touch. This human touch and rich meaning of life that makes Qianmen Street reflect a spirit of place, so that the street is full of multi-color, multi-exotic atmosphere of public life, but also makes people produce their sense of identity and sense of belonging.

Remodeling Qianmen Street, the main way to make it re-energize is to "the continuation of the old city social life, heritage spirit of place." to form "Beijing school culture" typical and representative, it is necessary to organize the collection of information by mining its form, manner and other activities, and then re-creation, then, demonstrated.

Development of experiential tourism. By arrangement visitors to participate in commercial or production activities or the development of private goods and other hotel visitors or residents to exchange with the owner, to understand old Beijing customs, traditions and crafts. This makes many of the traditional crafts, folk customs are preserved not only in the exhibition, handed, carry forward, inheritance, but also enhance tourism in the process of entertainment, fun. The effect of making the same strain theme, bring tourists "an unique" cultural tourism experience.

\section{Acknowledgements}

This work is supported by Tongji University Innovation Fund. I would like to express my gratitude to all those who helped me during the writing of this thesis.

\section{References}

[1] http : / / www . bj . xinhuanet . com / bjpd sdwII1 / 2009-10/15 / content 17956624. htm

[2] Jia Miao, Zhang Bin. Qianmen Area Historical Origin[J]. Architectural Creation,(2007)

[3] 3. Zhou Nan. Qianmen Street: commercial renaissance Rye[J]. Chinese market,(2009)

[4] Zhou Chun-yan. Old Beijing, New Beijing --Urban Consumption nature of the business landmark refracted[J]. Sales and Marketing Manager, (2013) 
[5] Selection paved rebirth road[J]. Investment Beijing, (2008)

[6] 6. http: / / news. xinhuanet. c0m / shuhua / 2013-10 / 15 / c 125540405. htm 